$$
\begin{array}{cc}
\left(\mathrm{C}_{2} \mathrm{H}_{3}\right)_{2} \mathrm{HAsO}_{4} & \left(\mathrm{C}_{4} \mathrm{H}_{5}\right)_{2} \mathrm{HAsO}_{4} \\
\text { Kakodylsäure } & \text { Aethylkakodylsäure } \\
\left(\mathrm{C}_{2} \mathrm{H}_{3}\right) \mathrm{H}_{2} \mathrm{AsO}_{6} & \left(\mathrm{C}_{4} \mathrm{H}_{6}\right) \mathrm{H}_{2} \mathrm{AsO}_{6} \\
\text { Arsenmonomethylsäure } & \text { Arsenmonoäthylsäure. }
\end{array}
$$

\title{
Ueber eine Verbindung von Chlorarsen und Alkohol;
}

$$
\text { von } V \text {. de Laynes* }{ }^{*} \text { ). }
$$

Bei dem Mischen von Chlorarsen und wasserfreiem Alkohol steigt die Temperatur bis etwa $70^{\circ}$; bei der Destillation geht dann bei $148^{\circ}$ eine bei dieser Temperatur siedende Verbindung von Chlorarsen und Alkohol über. Diese Verbindung läfst sich auch erhalten durch Einleiten von Chlorwasserstoffgas in Alkohol, in welchem arsenige Säure suspendirt ist; die arsenige Säure löst sich unter Temperalurerhöhung und es bilden sich zwei Schichten, deren untere bei $96^{\circ} \mathrm{zu}$ sieden beginnt und bei $148^{\circ}$, unter Constantbleiben dieser Temperatur, jene Verbindung übergehen läfst. Die Verbin-

\begin{tabular}{|c|c|c|c|}
\hline \multirow[b]{2}{*}{ Kohlenstoff } & \multicolumn{2}{|c|}{ gefunden } & berechnet \\
\hline & 9,5 & 9,6 & 10,9 \\
\hline Wasserstoff & 2,1 & 2,7 & 2,3 \\
\hline Chlor & 47,7 & 47,6 & 48,7 \\
\hline Arsen & & & 34,3 \\
\hline
\end{tabular}
dung von Chlorarsen und Alkohol ist farblos, raucht an der Luft, wird durch Wasser zu Salzsäure, arseniger Säure und Alkohol zersetzt, absorbirt unter Erwärmung viel Chlorwasserstoffgas, welches sie bei der Destillation wieder entweichen lälst. Sie ist wenig beständig, wird durch Feuchtigkeit rasch zersetzt, und zerlegt sich auch bei wiederholten Destillationen theilweise, unter Bildung von Chloräthyl u. a. Die Zusammensetzung schếint $\mathrm{C}_{4} \mathrm{H}_{6} \mathrm{O}_{2}, \mathrm{AsCl}_{3}$ zu sein :

Methyl- und Amylalkohol scheinen ähnliche Verbindungen $\mathrm{zu}$ geben.

*) Im Ausz, aus Compt. rend. L, 831. 